\title{
Histopathological findings of gastric specimens of patients undergoing sleeve gastrectomy
}

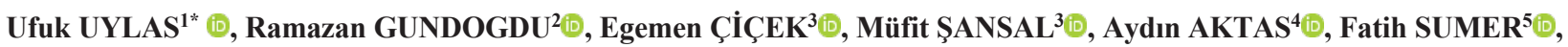 \\ Cuneyt KAYAALP'
}

\author{
${ }^{1}$ General Surgery Department, İzmir SBÜ Tepecik Training and Research Hospital, Izmir, Turkey \\ ${ }^{2}$ General Surgery Department, Adana Dr. Turgut Noyan Training and Research Hospital, Adana, Turkey \\ ${ }^{3}$ Gastroenterology Surgery Department, Hatay State Hospital, Malatya, Turkey \\ ${ }^{4}$ Gastrointestinal Surgery Department, Faculty of Medicine, Karadeniz Technical University, Trabzon, Turkey \\ ${ }^{5}$ Gastroenterology Surgery Department, Faculty of Medicine, Inonu University, Malatya, Turkey \\ ${ }^{6}$ Gastroenterology Surgery Department, Faculty of Medicine, Yeditepe University, Istanbul, Turkey
}

\begin{tabular}{l} 
Received: $23.01 .2020 \bullet \quad$ Accepted/Published Online: 30.01 .2021 \\
\hline Abstract \\
Sleeve gastrectomy is the most preferred surgical procedure in obese patients. In the literature, the necessity of pathological examination of the \\
specimen is emphasized because of malignant case reports. In this study, we aimed to present the histopathological findings of the specimens of \\
our patients who underwent sleeve gastrectomy due to obesity in the light of the literature. Patients who underwent sleeve gastrectomy due to \\
obesity between $2014-2019$ in our clinic were retrospectively screened. Endoscopy was not performed in patients with no symptoms. After the \\
obesity committee, the patients were operated and the specimens were sent for routine histopathological examination. Patients' age, gender, body \\
mass index, surgical procedure information, and histopathological features of resected gastric specimens were analyzed. A total of 411 patients \\
were included in the study and there were $309(75.2 \%)$ female patients. The overall mean age was $35 \pm 10.3$ and the mean body mass index was \\
$44.7 \pm 5.2 \mathrm{~kg} / \mathrm{m}^{2}$. The pathology of $85(20.7 \%)$ of the patients were reported as completely normal. Abnormal pathological findings were detected \\
in $326(79.3 \%)$ patients. No malignant finding was found in the specimen pathology results. The necessity of endoscopic examination before sleeve \\
gastrectomy is controversial. Even if no malignant pathological result was detected in our study, we believe that routine pathological examination \\
is required for medicolegal reasons.
\end{tabular}

Keywords: laparoscopy, sleeve gastrectomy, stomach, gastrointestinal stromal tumor, adenocarcinoma.

\section{Introduction}

The number of bariatric operations is gradually increasing with the increasing obesity in the world. According to the estimation of the World Health Organization, there is more than one billion overweight (body mass index $\geq 25$ ) and over 300 million obese (body mass index $\geq 30$ ) people worldwide (World Health Organization, 2009). The number of comorbidities such as hypertension, type 2 diabetes mellitus, stroke, cardiovascular diseases, and dyslipidemia is increasing with the increase in the number of obesity. It has been reported that approximately 6700 of 340000 surgical procedures performed worldwide in 2011 were bariatric surgery (Buchwald and Oien, 2013). Laparoscopic sleeve gastrectomy is the most common procedure among obesity procedures. Learning curve and application are easy also are other factors that increase the number of applications is the low morbidity and mortality.

Laparoscopic sleeve gastrectomy is an operation that has restrictive and endocrine effects but no malabsorptive effects.
Most of the stomach is removed and the stomach is turned into a tube. Incidental gastrointestinal stromal tumors, dysplasia, and maltoma can be seen as a result of pathological examination of the removed gastric specimen (Canil et al., 2018; Ricci et al., 2018). In this study, we aimed to investigate the presence of incidental precancerous lesions by pathological examination of sleeve gastrectomy specimens applied in our clinic and to present the findings to the literature.

\section{Materials and methods}

This retrospective study was conducted at Inonu University General Surgery Clinic in accordance with the ethical standards of the 1964 Helsinki declaration and its later amendments or comparable ethical standards. The study protocol was approved by our institutional Ethical Committee (no.2018/16-19). All patients who underwent sleeve gastrectomy due to obesity between June 2014 and August 2019 at Inonu University Faculty of Medicine General Surgery 
Clinic were retrospectively reviewed. Patients with missing data were excluded from the study. 411 patients whose data were available were included in the study. Preoperative informed consent was obtained from all patients in order to examine the resected samples and to use these samples appropriately in the study. Anesthesia consent was obtained after the obesity council made the operation decision. Endoscopy was not performed on patients without symptoms, since it was not in the routine of our clinic. Laparoscopic or open sleeve gastrectomy \pm additional surgical procedures were applied to the patients. Patients' age, gender, body mass index (BMI), surgical procedure information, and histopathological features of resected gastric specimens were analyzed. In statistical analysis, quantitative variables were expressed as mean $\pm \mathrm{SD}$, median, min-max, and range. Qualitative variables were reported as number and percentage (\%).

\section{Results}

$309(75.2 \%)$ of the patients included in the study were female and 102 (24.8) were male. The mean age in the whole group was $35 \pm 10.3$. While the mean age of men was $34.5 \pm 9.8$, it was $35.2 \pm 10.4$ for women. BMI was $44.7 \pm 5.2 \mathrm{~kg} / \mathrm{m}^{2}$ in the whole group. BMI of men was $45.5 \pm 5.3$, and for women, it was $44.4 \pm 5.2$ (Table 1$)$.

Table 1. Characteristics of 411 sleeve gastrectomy patients

\begin{tabular}{|l|l|l|l|} 
Gender & Number $(\%)$ & Age $($ mean \pm SD) & $\begin{array}{l}\text { BMI }(\text { mean } \pm \\
\text { SD) }\end{array}$ \\
\hline Male & $102(24.8)$ & $34.5 \pm 9.8$ & $45.5 \pm 5.3$ \\
Female & $309(75.2)$ & $35.2 \pm 10.4$ & $44.4 \pm 5.2$
\end{tabular}

There were patients who underwent additional procedures with sleeve gastrectomy. Only laparoscopic sleeve gastrectomy was performed in 361 patients. Seven of them were anastomosed manually without using a stapler. There were $19,17,3,1$, and 1 patient who underwent laparoscopic sleeve gastrectomy with cholecystectomy, jejunoileal bypass (JIB), cruroraphy, JIB + cholecystectomy, and left adrenalectomy, respectively. There were seven patients who underwent open sleeve gastrectomy alone. There was one patient each who underwent cholecystectomy and cholecystectomy + tubal ligation + incisional hernia repair together with open sleeve gastrectomy (Table 2).

No specific pathological finding was observed in 85/411 $(20.7 \%)$ of the patients and it was reported as normal. Specific pathological findings were present in 326 (79.3\%) patients. Helicobacter pylori presence in Giemsa dye was found in 200 (48.7\%) patients. Of these, 60/65 (92.3\%) were accompanied by chronic active gastritis and 140/257 (54.4\%) were accompanied by chronic inactive gastritis. Chronic inactive gastritis 257 (62.5\%), Chronic active gastritis 65 (15.8), intestinal metaplasia $17(4.1 \%)$, proton pump inhibitor (PPI) affect 4 (1\%), low degree dysplasia 2 (0.5\%), Atrophic chronic gastritis $1(0.2 \%)$, ectopic pancreas was reported in $1(0.2 \%)$ patient (Table 3 ).
Tablo 2. Characteristics of surgery for 411 sleeve gastrectomy patients

\begin{tabular}{|l|l|}
\hline Surgery & Number \\
\hline $\begin{array}{l}\text { Laparoscopic sleeve gastrectomy } \\
\text { Laparoscopic sleeve gastrectomy + cholecystectomy }\end{array}$ & 354 \\
\hline $\begin{array}{l}\text { Laparoscopic sleeve gastrectomy + JIB } \\
\text { Laparoscopic sleeve gastrectomy without staple }\end{array}$ & 17 \\
\hline $\begin{array}{l}\text { Open sleeve gastrectomy } \\
\text { Laparoscopic sleeve gastrectomy + cruroraphy }\end{array}$ & 7 \\
\hline $\begin{array}{l}\text { Laparoscopic sleeve gastrectomy + JIB + } \\
\text { cholecystectomy }\end{array}$ & 1 \\
\hline $\begin{array}{l}\text { Open sleeve gastrectomy + cholecystectomy } \\
\text { Open sleeve gastrectomy + cholecystectomy + tubal }\end{array}$ & 1 \\
\hline $\begin{array}{l}\text { ligation + incisional hernia repair } \\
\text { Laparoscopic sleeve gastrectomy + left } \\
\text { adrenalectomy }\end{array}$ & 1 \\
\hline
\end{tabular}

JIB: jejuno-ileal bypass

\section{Discussion}

Abnormal histopathological findings include a wide spectrum from chronic inactive gastritis to a gastrointestinal stromal tumor. However, the rate of not finding any specific pathological findings in the histopathological examination of the specimen in sleeve gastrectomy has been reported to vary between 0-80.2\% (Almazeedi et al., 2013; Miller et al., 2016). In our study, the specimen pathology did not contain specific findings in $85(20.7 \%)$ patients.

Tablo 3. Histopathology of 411 sleeve gastrectomy specimen

\begin{tabular}{|l|l|}
\hline Histopathology & Number (\%) \\
\hline $\begin{array}{l}\text { Normal (no specific histopathologic } \\
\text { change) }\end{array}$ & $85(20.7)$ \\
\hline $\begin{array}{l}\text { Abnormal (specific histopathologic } \\
\text { change evident) }\end{array}$ & $326(79.3)$ \\
\hline $\begin{array}{l}\text { Chronic inactive gastritis } \\
\text { Helicobacter pylori }\end{array}$ & $257(62.5)$ \\
\hline \multicolumn{1}{|c|}{ In chronic active gastritis } & $200(48.7)$ \\
\hline Chronic active gastritis & $140(54.4)$ \\
\hline $\begin{array}{l}\text { Intestinal metaplasia } \\
\text { Proton pomp inhibitor affect }\end{array}$ & $60(92.3)$ \\
\hline $\begin{array}{l}\text { Low grade dysplasia* } \\
\text { Atrophic chronic gastritis }\end{array}$ & $65(15.8)$ \\
\hline Ectopic pancreas & $17(4.1)$ \\
\hline
\end{tabular}

*both low grade dysplasia were accompanied by intestinal metaplasia. ๆ low-grade dysplasia and intestinal metaplasia accompanied atrophic gastritis.

There are two forms of chronic gastritis, active and inactive. In the histopathological examination of sleeve 
gastrectomy specimens, the rates of chronic active and inactive gastritis were reported to be $1.6-35 \%$ and $12.1-74.5 \%$, respectively (Almazeedi et al., 2013; Ohanessian et al., 2016; Dogan et al., 2017; Raess et al., 2015). In our study, chronic active gastritis was detected in $65 / 411(15.8 \%)$ patients and chronic inactive gastritis in $257 / 411$ (62.5\%) patients. The high presence of Helicobacter pylori indicates that many patients need to be treated. However, in the follow-up of these patients, Helicobacter pylori infection has been shown to be a disease that does not cause peptic ulcer and cancer. Helicobacter pylori was not detected in the majority of urea breath tests performed after surgery. It has been suggested that as a result of removing most of the stomach, the rate of Helicobacter pylori decreases as the stomach volume decreases. It has been stated that eradication of this Helicobacter pylori infection will cause unnecessary time and cost, especially in non-symptomatic patients (Keren et al., 2009). In the specimen, there were 200 (48.7) patients with signs of Helicobacter pylori-associated gastritis. Dysplasia can be seen at a rate of $0.06-0.2 \%$ in the histopathological examination of sleeve gastrectomy specimens (Canil et al., 2018; Safaan et al., 2017). These patients need to be followed up strictly. Intestinal metaplasia can be detected at a rate of $0.2-5 \%$ and atrophic gastritis with a rate of 0.2-1.8\% (Canil et al., 2018; Almazeedi et al., 2013). In our series, low-grade dysplasia was seen in $2(0.5 \%)$ patients, intestinal metaplasia in $17(4.1 \%)$, and atrophic gastritis in 1 $(0.5 \%)$. One of the two patients with dysplasia had only intestinal metaplasia; the other was accompanied by atrophic gastritis and intestinal metaplasia.

The incidence of gastric cancer after sleeve gastrectomy is very rare (Scozzari et al., 2013). Gastroesophageal reflux is more common in obese patients. It can cause erosive esophagitis, barret esophagitis, and gastroesophageal junction cancer (Nilsson and Lagergren, 2004). However, there are also cases with cancer development in the antrum and corpus of the stomach remaining after sleeve gastrectomy (Seki et al., 2018; Vladimirov et al., 2017; Yamashita et al., 2019). Chronic gastritis, H.pylori, and smoking are among the risk factors for stomach cancer (Uemura et al., 2001). Pre-operative eradication of H.pyronine can reduce the risk of cancer development. Preoperative endoscopy and removal if there are premalignant lesions are recommended (Lee et al., 2017). Endoscopic removal of premalignant lesions after surgery is not possible due to the narrow area. However, there are centers in the literature that perform preoperative routine endoscopy as well as selective endoscopy (Safaan et al., 2017; Lauti et al., 2016; Solmaz et al., 2018). In our clinic, we do the endoscopy selective rather than routine.

The rate of gastrointestinal stromal tumors in specimen pathologies ranges from $0.1-1.2 \%$ (Canil et al., 2018; Kinsinger et al., 2016). In addition, the rate of gastrointestinal stromal tumor detection was found to be $17.3 \%$ in one series (Walędziak et al., 2017). The total number of patients in this series was 1252 , and only the pathology of 81 patients they deemed suspicious was examined. Therefore, it does not reflect the total incidence since the rate was so high. In our series, $20.9 \%$ normal histopathology was detected, and no gastrointestinal stromal tumor was detected. Routine histopathological evaluation is not recommended due to the low incidence of benign and malignant lesions in large clinical series and the majority of lesions. In addition, the histopathological findings found do not correlate with postoperative complications and management of complications. It is thought that performing a microscopic examination of necessary specimens as a result of a careful macroscopic examination will be better in terms of cost and time (AbdullGaffar et al., 2016). In gastric pathology after sleeve gastrectomy, $58(0.46 \%)$ patients had tumors, and one of these patients was found to have adenocarcinoma (Aljerian, 2018).

In our study, gastrointestinal stromal tumors and other malignant tumors were not detected, and we think that the reason for the higher rate of dysplasia compared to the literature may be the low number of patients. The reason for our low number of patients is that patients in our clinic prefer more laparoscopic Roux-N-Y gastric bypass. In some studies, clinics stated that they stopped routine examinations (Dogan et al., 2017; Crouthamel et al., 2015). Sleeve gastrectomy can be performed with increasing frequency and safety. Routine preoperative endoscopy before these operations is still a controversial issue. Although rare, malignant cases have been reported in the literature as a result of specific pathology. Even if no malignant pathological result was detected in our study, we believe that routine pathological examination is required for medicolegal reasons

\section{Conflict of interest}

None to declare.

\section{Acknowledgments}

None to declare.

\section{References}

1- World Health Organization., 2009, Global health risks: mortality and burden of disease attributable to selected major risks. Geneva, World Health Organization.

2- Buchwald, H., Oien, D.M., 2013. Metabolic/bariatric surgery worldwide 2011. Obes. Surg. 23, 427-436.

3- Canil, A.M., Iossa, A., Termine, P., Caporilli, D., Petrozza, V., Silecchia, G., 2018. Histopathology Findings in Patients Undergoing Laparoscopic Sleeve Gastrectomy. Obes. Surg, 28, 1760-1765.

4- Ricci, C., Agostinelli, C., Ambrosi, F., Garell, S., Zinzani, P.L., Rottoli, M., Sabattini, E., 2018. Gastric MALT Lymphoma in a Sleeve Gastrectomy Specimen: Case Report and Literature Review. Bariatr. Surg. Pract. Patient. Care. 13, 90-93.

5- Almazeedi, S., Al-Sabah, S., Al-Mulla, A., Al-Murad, A., AlMossawi, A., Al-Enezi, K., Jumaa, T., Bastaki, W., 2013. Gastric histopathologies in patients undergoing laparoscopic sleeve gastrectomies. Obes. Surg. 23, 314-319.

6- Miller, G.C., Reid, A.S., Brown, I.S., 2016. The pathological findings seen in laparoscopic sleeve gastrectomies for weight 
loss. Pathology. 48, 228-232.

7- Ohanessian, S.E., Rogers, A.M., Karamchandani, D.M., 2016. Spectrum of Gastric Histopathologies in Severely Obese American Patients Undergoing Sleeve Gastrectomy. Obes. Surg. 26, 595-602.

8- Dogan, U., Suren, D., Oruc, M.T., Gokay, A.A., Mayir, B., Cakir, T., Aslaner, A., Oner, O.Z., Bulbuller, N.,2017. Spectrum of gastric histopathologies in morbidly obese Turkish patients undergoing laparoscopic sleeve gastrectomy. Eur. Rev. Med. Pharmacol. Sci. 21, 5430-5436.

9- Raess, P.W., Baird-Howell, M., Aggarwal, R., Williams, N.N., Furth, E.E., 2015. Vertical sleeve gastrectomy specimens have a high prevalence of unexpected histopathologic findings requiring additional clinical management. Surg. Obes. Relat. Dis. $11,1020-1023$.

10- Keren, D., Matter, I., Rainis, T., Goldstein, O., Stermer, E., Lavy, A., 2009. Sleeve gastrectomy leads to Helicobacter pylori eradication. Obes. Surg. 19, 751-756.

11- Safaan, T., Bashah, M., El Ansari, W., Karam, M., 2017. Histopathological Changes in Laparoscopic Sleeve Gastrectomy Specimens: Prevalence, Risk Factors, and Value of Routine Histopathologic Examination. Obes. Surg. 27, 1741-1749.

12- Scozzari, G., Trapani, R., Toppino, M, Morino, M., 2013. Esophagogastric cancer after bariatric surgery: systematic review of the literature. Surg. Obes. Relat. Dis. 9, 133-142.

13- Nilsson, M., Lagergren, J., 2014. The relation between body mass and gastro- oesophageal reflux. Best. Pract. Res. Clin. Gastroenterol. 18, 1117-11123.

14- Seki, Y., Kasama, K., Tanaka, T., Baba, S., Ito, M., Kurokawa, Y., 2018. Early gastric cancer successfully treated by endoscopic submucosal resection 1 year after laparoscopic sleeve gastrectomy with duodenal-jejunal bypass. Asian. J. Endosc. Surg. 12, 357-361.

15- Vladimirov, M., Hesse, U., Stein, HJ., 2017. Gastric carcinoma after sleeve gastrectomy for obesity. Surg. Obes. Relat. Dis. 13, 1459-1461.

16- Yamashita, T., Tan, J., Lim, E., Eng, A., Ong, H.S., Chan, W.H., 2019. A case of gastric cancer after sleeve gastrectomy. Asian J.
Endosc. Surg, 13, 586-591

17- Uemura, N., Okamoto, S., Yamamoto, S., Matsumura, N., Yamaguchi, S., Yamakido, M., Taniyama, K., Sasaki, N., Schlemper, R. J., 2001. Helicobacter pylori infection and the development of gastric cancer. N. Engl. J. Med. 345, 784-789.

18- Lee, J., Wong, S. K., Liu, S. Y., Ng, E. K., 2017. Is preoperative upper gastrointestinal endoscopy in obese patients undergoing bariatric surgery mandatory? An Asian perspective. Obes. Surg. $27,44-50$.

19- Safaan, T., Bashah, M., El Ansari, W., Karam, M.,2017 Histopathological changes in laparoscopic sleeve gastrectomy specimens: prevalence, risk factors, and value of routine histopathologic examination. Obes. Surg. 27, 1741-1749.

20- Lauti, M., Gormack, S.E., Thomas, J.M., Morrow, J.J., Rahman, H., MacCormick, A.D., 2016. What does the excised stomach from sleeve gastrectomy tell us? Obes. Surg. 26, 839-842.

21- Solmaz, Ö.A., Akyol, H., Erol, F., 2018. Histopathological findings and helicobacterpylori infection frequency in 816 sleeve gastrectomy materials for morbid obesity. Laparosc. Endosc. Surg. Sci. 25, 93-97.

22- Kinsinger, L.A., Garber, J.C., Whipple, O., 2016. A review of sleeve gastrectomy specimen histopathology. Am. Surg. 82, 1101-1104.

23- Walędziak, M., Różańska-Walędziak, A., Kowalewski, P.K., Janik, M.R., Brągoszewski, J., Paśnik, K., 2017. Bariatric surgery and incidental gastrointestinal stromal tumors - a singlecenter study: VSJ Competition, 1(st) place. Wideochir Inne Tech Maloinwazyjne, 12, 325-329.

24- AbdullGaffar, B., Raman, L., Khamas, A., AlBadri, F.,2016. Should we abandon routine microscopic examination in bariatric sleeve gastrectomy specimens? Obes. Surg. 26, 105-110.

25- Aljerian, K., 2018. Histopathological Findings in Laparoscopic Sleeve Gastrectomy Specimens from Patients with Obesity in Saudi Arabia. Gastroenterol. Res. Pract. 2018, 1702705.

26- Crouthamel, M.R., Kaufman, J.A., Billing, J.P., Billing, P.S., Landerholm, R.W., 2015. Incidental gastric mesenchymal tumors identified during laparoscopic sleeve gastrectomy. Surg. Obes. Relat. Dis. 11, 1025-1028. 